\title{
MONOSYNAPTIC INPUTS TO EXCITATORY AND INHIBITORY NEURONS OF THE INTERMEDIATE AND DEEP LAYERS OF THE SUPERIOR COLLICULUS
}

\section{Abbreviated title: MONOSYNAPTIC INPUTS TO SUPERIOR COLLICULUS}

Ted K. Doykos ${ }^{1,2}$, Jesse I. Gilmer ${ }^{1,2}$, Abigail L.Person ${ }^{1,2, *}$, Gidon Felsen ${ }^{1,2, *}$

\author{
${ }^{1}$ Neuroscience Graduate Program, University of Colorado School of Medicine, Aurora, CO 80045 USA \\ ${ }^{2}$ Department of Physiology \& Biophysics, University of Colorado School of Medicine, Aurora, CO 80045 USA \\ *Joint senior authors
}

\section{ACKNOWLEDGEMENTS}

We thank Nathan D. Baker for help with histology and imaging. Light microscopy was performed at the University of Colorado Anschutz Medical Campus Advance Light Microscopy Core supported in part by Rocky Mountain Neurological Disorders Core Grant Number P30NS048154. This work was supported by the NIH/NINDS (R01NS079518) and NIH (R01NS084996). 


\section{ABSTRACT}

The intermediate and deep layers of the midbrain superior colliculus (SC) are a key locus for several critical functions, including spatial attention, multisensory integration and behavioral responses. While the SC is known to integrate input from a variety of brain regions, progress in understanding how these inputs contribute to SC-dependent functions has been hindered by the paucity of data on innervation patterns to specific types of

SC neurons. Here, we use G-deleted rabies virus-mediated monosynaptic tracing to identify inputs to excitatory and inhibitory neurons of the intermediate and deep SC. We observed stronger and more numerous projections to excitatory than inhibitory SC neurons. However, a subpopulation of excitatory neurons thought to mediate behavioral output received weaker inputs, from far fewer brain regions, than the overall population of excitatory neurons. Additionally, extrinsic inputs tended to target rostral excitatory and inhibitory SC neurons more strongly than their caudal counterparts, and commissural SC neurons tended to project to similar rostrocaudal positions in the other SC. Our findings support the view that active intrinsic processes are critical to SCdependent functions, and will enable the examination of how specific inputs contribute to these functions.

\section{KEYWORDS:}

Monosynaptic, Excitatory, Inhibitory, Superior Colliculus, Neuroanatomy, Sensorimotor, Rabies 


\section{INTRODUCTION}

The superior colliculus (SC) is a highly conserved midbrain structure critical for orienting behavior (Basso and May, 2017), as well as other associated functions such as spatial attention (Krauzlis et al., 2013) and multisensory integration (Stein and Stanford, 2008). The SC is organized into a superficial visual layer, which receives projections from the retina (Apter, 1945) and descending inputs from the neocortex (Kawamura et al., 1974), and intermediate and deep layers $\left(\mathrm{SC}_{\mathrm{id}}\right)$ that receive widespread input from several cortical and subcortical regions (Sparks and Hartwich-Young, 1989). The $\mathrm{SC}_{\mathrm{id}}$ is organized into a topographic map of movement space, whereby small amplitude orienting movements are encoded rostrally and larger amplitude movements are represented caudally (Robinson, 1972; Wang et al., 2015). While much of our understanding of the role of the $\mathrm{SC}_{\mathrm{id}}$ during behavior originated with work in primates making saccades to visual targets (Goldberg and Wurtz, 1972a; b; Wurtz and Goldberg, 1972; Lee et al., 1988), other work across a wider range of species points to a broader involvement of the $\mathrm{SC}_{\mathrm{id}}$ (or the optic tectum (OT) the nonmammalian homologue of the SC) in other orienting behaviors (Sparks, 1999). For example, $\mathrm{SC}_{\mathrm{id}} / \mathrm{OT}$ activity encodes orienting movements of the head in cats (Guillaume and Pélisson, 2001), monkeys (Freedman et al., 1996; Corneil et al., 2002; Walton et al., 2007), owls (du Lac and Knudsen, 1991), frogs (Meyer and Sperry, 1973), and bats (Valentine et al., 2002). $\mathrm{SC}_{\mathrm{id}} / \mathrm{OT}$ neural activity also controls limb movements in cats (Courjon et al., 2004, 2015), monkeys (Werner et al., 1997; Philipp and Hoffmann, 2014), and mice (Steinmetz et al., 2018) as well as full body orienting movements in goldfish (Herrero et al., 1998) and rodents (Felsen and Mainen, 2008; Stubblefield et al., 2013). In addition to its role in orienting to targets across a wide range of evolutionarily diverse species, the SC is also critical for producing escape behavior away from aversive stimuli (Dean et al., 1986, 1989; Sahibzada et al., 1986).

Alongside our understanding of the $\mathrm{SC}_{\mathrm{id}}$ 's roles in behavior, a great deal is also known about which brain centers project to the $\mathrm{SC}_{\mathrm{id}}$ (Edwards et al., 1979; Sparks and Hartwich-Young, 1989; Wolf et al., 2015). Several studies have employed anterograde and/or retrograde tracers demonstrating $\mathrm{SC}_{\mathrm{id}}$ afferents originating from cerebral cortex (Garey et al., 1968; Edwards et al., 1979; Fries, 1984), thalamic areas (Edwards et al., 1974, 1979; Graybiel, 1974; Grofová et al., 1978), cerebellar nuclei (Batton et al., 1977; Kawamura et al., 
1982), and several mesencephalic regions (Hopkins and Niessen, 1976; Grofová et al., 1978; Edwards et al., 1979). Potential roles for individual $\mathrm{SC}_{\mathrm{id}}$ afferents range from transmitting behaviorally-relevant information about visual input (frontal eye field (FEF): Segraves and Goldberg, 1987; Sommer and Wurtz, 2000, 2001;

Wurtz et al., 2001; lateral interparietal cortex: Paré and Wurtz, 2001; Wurtz et al., 2001; V1: Liang et al., 2015), recent experience (FEF: Sommer and Wurtz, 2001; M2: Duan et al., 2019), and target value (substantia nigra pars reticulata (SNr): Handel and Glimcher, 2000; Basso and Wurtz, 2002; Sato and Hikosaka, 2002; Bryden et al., 2011), to more active roles such as saccade initiation (FEF: Schiller et al., 1980; Hanes and Wurtz, 2001) and cessation (cerebellum: Goffart et al., 1998).

While these and other studies point to an integrative role for the SC in mediating behavior (Wolf et al., 2015), the $\mathrm{SC}_{\mathrm{id}}$ itself contains a variety of cell types, and in order to fully elucidate its functional circuitry we need to better understand its cell-type-specific inputs (Oliveira and Yonehara, 2018; Masullo et al., 2019). As a first step, we focused on inputs to excitatory and inhibitory $\mathrm{SC}_{\mathrm{id}}$ neurons (“eSCNs" and "iSCNs," respectively). The $\mathrm{SC}_{\mathrm{id}}$ is composed of $\sim 70 \%$ glutamatergic cells and $\sim 30 \%$ GABAergic cells (Mize, 1992) each with projection patterns within and between SC layers, to the contralateral SC, and out of the SC (Pettit et al., 1999; Isa and Hall, 2009; Sooksawate et al., 2011; Ghitani et al., 2014), suggesting that the interactions between eSCNs and iSCNs may play a key role in the $\mathrm{SC}_{\mathrm{id}}$ computations underlying orienting behaviors. Thus, a critical piece of understanding $\mathrm{SC}_{\mathrm{id}}$ function lies in discovering the specific projection patterns to eSCNs and iSCNs. Recent technological advances in mouse transgenics (Branda and Dymecki, 2004) and transsynaptic tracers (Wickersham et al., 2007; Wall et al., 2010; Luo et al., 2018) have allowed us to probe the organization of microcircuits with greater specificity. Thus, we leveraged Cre-lox recombination in conjunction with a transsynaptic retrograde rabies virus tracer strategy to label monosynaptic inputs to eSCNs and iSCNs, as well as to a subset of brainstem-projecting eSCNs neurons thought to drive orienting movements (Sooksawate et al., 2005, 2008). We found that projection patterns differed to these populations, suggesting cell-type-specific input integration, which has important implications for $\mathrm{SC}_{\mathrm{id}}$ function. 


\section{Animals}

All procedures followed the National Institutes of Health Guidelines and were approved by the Institutional Animal Care and Use Committee at the University of Colorado Anschutz Medical Campus. Animals were housed in an environmentally controlled room, kept on a 12-hour light/dark cycle and had ad libitum access to food and water. Adult mice of both sexes were used in these experiments ( $\mathrm{n}=7$ males; $\mathrm{n}=5$ females). All mice were adult C57BL/6 (including Jackson labs homozygous Vglut2-Cre (RRID: IMSR_JAX:028863, Vong et al., 2011) and heterozygous Gad2-Cre (RRID: IMSR_JAX:010802, Taniguchi et al., 2011)) bred in house.

\section{Viral injections}

AAV1-EF1.Flex.TVA.mCherry (UNC Vector Core; Watabe-Uchida et al., 2012) and AAV9.Flex.H2B.GFP.2A.oG (Salk Gene Transfer, Targeting and Therapeutics Core; Kim et al., 2016) were coinjected (100 nL of each; vortexed together after combining in equal proportions; Fig. 1A) unilaterally into the $\mathrm{SC}_{\mathrm{id}}$ of Vglut2-Cre, Gad2-Cre, and wild-type mice. After a three week incubation period, a second injection of EnvA.SAD $\Delta$ G.eGFP virus was made at the same location (Salk Gene Transfer, Targeting and Therapeutics Core; Wickersham et al., 2007; Wall et al., 2010; Kim et al., 2016; Fig. 1A). Rabies virus injections (400 nL) were made at a $20^{\circ}$ angle relative to vertical to avoid labeling cells in the superficial SC. Injection coordinates were varied along the rostrocaudal and dorsoventral axes and were made at $-0.75 \mathrm{~mm}$ or $-0.8 \mathrm{~mm}$ with respect to the midline. Mice were then sacrificed after an additional week and prepared for histological examination.

In experiments where rabies virus infection was targeted to $\mathrm{SC}_{\mathrm{id}}$ output neurons, the above-described procedures were followed except wild-type mice were used and during the first surgery a retrograde Cre virus (CAV2-Cre; Peltékian et al., 2002) was injected into the medial pontine reticular formation (MPRF) contralateral to the injected $\mathrm{SC}_{\mathrm{id}}$, a structure known to receive inputs from the $\mathrm{SC}_{\mathrm{id}}$ (Huerta and Harting, 1982; Redgrave et al., 1990; Isa and Sasaki, 2002). 

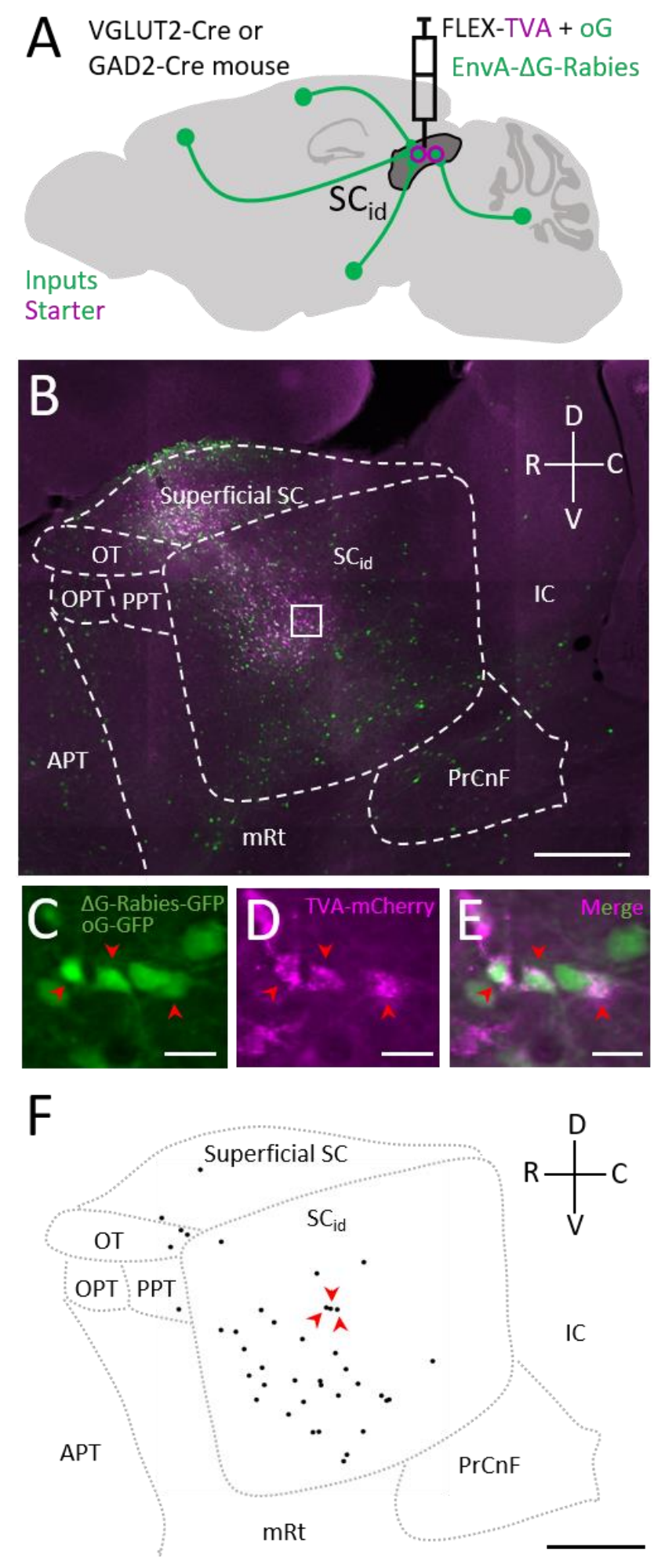

\section{Tissue preparation and imaging}

Mice were overdosed with an intraperitoneal injection of a sodium pentobarbital solution,

Pentobarbital (Sigma-Aldrich Inc.), and perfused transcardially with $0.9 \%$ saline followed by $4 \%$ paraformaldehyde. Brains were removed and postfixed for 4-24 hours then cryoprotected in 30\% sucrose. Tissue was sliced in $40 \mu \mathrm{m}$ serial sagittal sections using a freezing microtome and stored in 0.1 M phosphate buffered saline. Every third section was Nissl stained (Thermo Fisher Scientific, Cat\# N21483, RRID: AB_2572212), mounted onto slides, and imaged in three colors using a slidescanning microscope (Leica DM6000B

Figure 1. Rabies expression and identification of starter neurons

(A) Experimental strategy for targeting rabies virus to eSCNs and iSCNs. (B) Example image of an $\mathrm{SC}_{\mathrm{id}}$ injection site. Green: oG-GFP and Rabies-GFP. Magenta: TVAmCherry. White box indicates magnified area shown in C$\mathrm{E}$, and dashed outlines depict borders of the $\mathrm{SC}_{\mathrm{id}}$ and surrounding brain areas. (C-E) Boxed area in B. Arrowheads indicate double-labeled starter neurons. (F) Dots indicate the location of the identified starter neurons displayed in panel B. Arrowheads indicate the starter neurons highlighted in C-E. Scale bars: $500 \mu \mathrm{m}(\mathrm{B}, \mathrm{F}) ; 20$ $\mu \mathrm{m}$ (C-E). Abbreviations: anterior pretectal nucleus (APT); inferior colliculus (IC); mesencephalic reticular formation (mRt); olivary pretectal nucleus (OPT); nucleus of the optic tract (OT); posterior pretectal nucleus (PPT); precuneiform area $(\mathrm{PrCnF})$.

Epifluorescence \& Brightfield Slide Scanner; Leica HC PL APO 10x Objective with a 0.4 numerical aperture air; Objective Imaging Surveyor, V7.0.0.9 MT). Images were then converted to TIF files (OIViewer

Application V9.0.2.0) for subsequent analysis. An additional set of images used for starter neuron analysis were acquired in sections near the injection site. 
Images of input neurons displayed in Figure 2 were acquired with an Olympus IX81 with a disk scanning unit for confocal imaging (Olympus UPlanFL 20x Objective, 0.5 numerical aperture air) controlled with $\mu$ Manager software (https://micro-manager.org/, RRID: SCR_016865, Edelstein et al., 2010, 2014). Tile correction was performed in ImageJ (https://imagej.net/, RRID: SCR_003070, Rueden et al., 2017)/FIJI (http://fiji.sc, RRID: SCR_002285, Schindelin et al., 2012; Peng et al., 2017).

\section{Starter neuron quantification and brain area classification:}

Rabies positive "starter neurons" were identified in ImageJ (FIJI) based on the following criteria: 1) the presence of GFP and mCherry, 2) visible neurites (Fig. 1C-E), and 3) fully overlapping mCherry-GFP signal. Neurons in which the mCherry signal extended beyond the borders of the GFP signal were not counted, since such labeling was more consistent with overlap of histone-tagged oG-GFP, not rabies-GFP, which readily fills cells.

Starter neuron coordinates were then exported to a MATLAB (http://www.mathworks.com/products/matlab/, RRID: SCR_001622) custom-written image viewer and classified as being within the $\mathrm{SC}_{\mathrm{id}}$, the superficial $\mathrm{SC}$, or any other region. Animals were only included in analyses if the majority of their starter neurons were located within the SC and the majority of those neurons were located within the $\mathrm{SC}_{\mathrm{id}}$.

\section{Input neuron quantification and brain area classification:}

GFP-expressing input neurons were automatically identified using a semantic segmentation artificial neural network (SSN). The SSN was trained in MATLAB (Computer Vision System Toolbox) using customwritten scripts, to identify somata based on previously identified cell morphological data.

We used an initial training set of 4327 labelled images from 44 tissue sections obtained from 6 mice. 2581 of the sample images were images of known cells, and the remaining 1746 were images that were verified not to contain any cells, to provide examples of negative data. Each image was a 200 x 200 pixel image either centered on the cell coordinates, or arbitrarily chosen from the images of the sections. Tissue containing labeled 
and unlabeled neurons was used for semantic labeling in the training set. Cell body morphology was estimated by taking pre-identified soma coordinates and using the MATLAB 'regionprops' function to isolate features in the selected images. This process was optimized to find the human-identified cells within an image. If the cell body boundaries could not be resolved algorithmically, a circle with a radius of six pixels was drawn centered on the cell coordinates instead.

The extracted images were prepared for SSN usage using a custom MATLAB script, and the network was trained iteratively to optimize accuracy, using the following method: after each round of training and scoring, misses were saved as an image and replicated in the training data pool, and false positives were added to the negative image training pool. After several iterations, the final training dataset contained 16,443 images.

To validate that the network performed at an accuracy similar to a human observer, three experimenters who had not previously labelled images (A.P., G.F., and J.G.) performed the image coordinate identification process on 5 sample images. The agreement in labeling between the SSN and experimenters was comparable to inter-experimenter agreement (agreement between experimenters on detected cells: $69.1 \% \pm 6.3 \%$ of all cells [standard deviation]; experimenter agreement with deep learning algorithm: 70.7\% $\pm 8.3 \%$ [standard deviation]).

A quality control step was added to ensure that machine identified neurons were in agreement with human assessment. Each machine identified neuron was output as an image, and false positives were manually deleted. Thus, the final dataset included only neurons remaining after manual curation. The coordinates of SSN identified neurons were then exported to a MATLAB custom-written image viewer and classified according to brain area based on a standard mouse atlas (Paxinos and Franklin, 2013). We mainly focused on descending projections that were sufficiently far from the injection site to exclude contamination by starter neurons (See Results).

\section{Starter and input neuron analyses}

Input neuron counts in each brain area were normalized to the number of $\mathrm{SC}_{\mathrm{id}}$ starter neurons in that mouse to yield a measure of "projection strength", a standard metric to correct for variability in viral expression 
(Watabe-Uchida et al., 2012; Sun et al., 2014). Subsequent analyses of projection strength were performed in MATLAB. Brain areas included in analyses comparing eSCNs to iSCNs had projection strengths to eSCNs or iSCNs > 0.01 (> 1 input neuron per 100 starter neurons). Areas with projection strengths to iSCNs $>0.005$ were used in Figure 5C and 5D. The laterality preference in Figure 4 was computed as: $L P=(2 \times C)-1$, where $C$ is the fraction of contralateral inputs. This yielded normalized values between -1 (strongest ipsilateral preference) and 1 (strongest contralateral preference). Random inputs in Figure 7F were obtained by averaging iterations of randomly generated input neuron positions (1000 iterations; 1707 random input neuron positions [eSCNs] or 145 random input neuron positions [iSCNs] per iteration).

The normalized rostrocaudal positions of starter and input neurons used in Figures 5 and 7 were obtained by setting the rostral-most and caudal-most extents of the $\mathrm{SC}_{\mathrm{id}}$ in each section to 0 and 1 , respectively, and determining the fractional location of each neuron along the rostrocaudal axis.

\section{RESULTS}

\section{Rabies expression and identification of starter neurons}

We used a modified rabies virus, EnvA- $\Delta$ G-Rabies-GFP, to transsynaptically label neurons projecting monosynaptically to eSCNs in Vglut2-Cre (RRID: IMSR_JAX:028863, Vong et al., 2011) or iSCNs in Gad2Cre mice (RRID: IMSR_JAX:010802, Taniguchi et al., 2011; Fig. 1A). Cell-type specificity of viral infection and spread was achieved using a Cre-dependent trans-complementation strategy (Wickersham et al., 2007; Wall et al., 2010; Watabe-Uchida et al., 2012; Kim et al., 2016; Beitzel et al., 2017). The majority of rabies "starter" neurons were located within the $\mathrm{SC}_{\mathrm{id}}$ (Fig. $\left.2 \mathrm{~B}, \mathrm{~F}\right)$. Only cells with visible neurites that were both $\mathrm{GFP}+$ and mCherry+ were classified as starter neurons (see Materials and Methods; Fig. 1C-E). Subsequent analyses were then used to identify input neurons and map them according to brain area (see Materials and Methods). Neuron counts in each area were then normalized to the number of $\mathrm{SC}_{\mathrm{id}}$ starter neurons to yield a measure of "projection strength", a standard metric to correct for variability in viral expression (Watabe-Uchida et al., 2012; Sun et al., 2014). Using this approach we quantified projection patterns to eSCNs and iSCNs. 

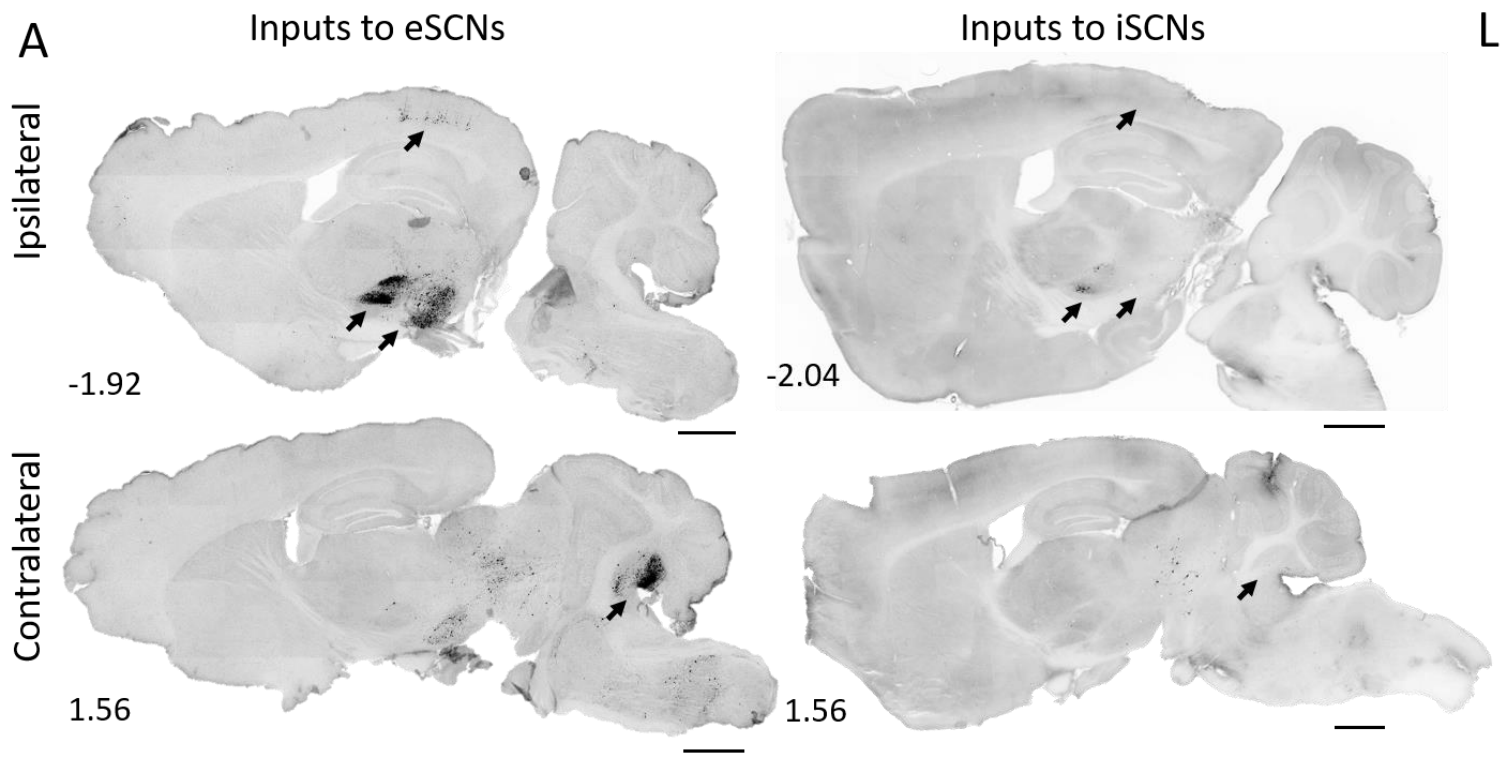

\section{L $\underline{\text { Injection sites }}$

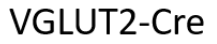

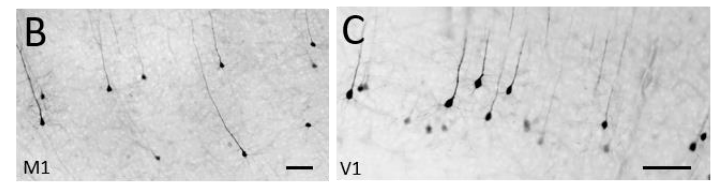
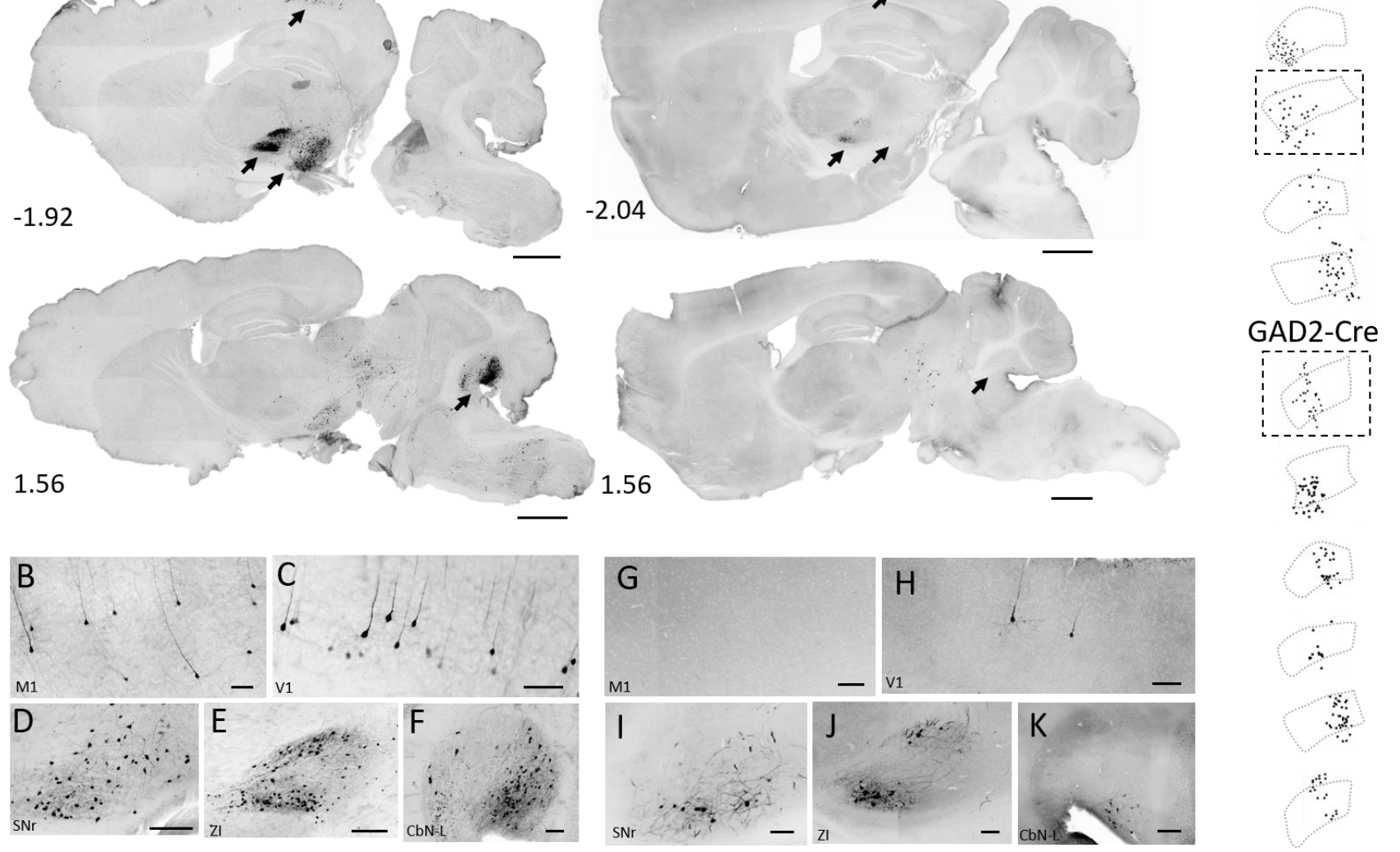

Figure 2. eSCNs receive more extrinsic inputs than iSCNs

Representative sagittal sections depicting inputs ipsilateral (top row) and contralateral (bottom row) to the injected $\mathrm{SC}_{\text {id }}$ in $\mathrm{Vglut}_{\text {gl- }}$ Cre (left column) and Gad2-Cre mice. Distance of section from midline (in $\mathrm{mm}$ ) indicated by values in the lower left corner. (B-K) Representative images of input neurons to eSCNs (B-F) and iSCNs (G-K). Scale bars: $1 \mathrm{~mm}$ (A); $100 \mu \mathrm{m}$ (B-K). (L) Injection sites depicting $\mathrm{SC}_{\mathrm{id}}$ (gray dashed outline) and location of identified starter neurons (black dots) in a representative sagittal plane (between $0.36 \mathrm{~mm}$ and $1.08 \mathrm{~mm}$ lateral to midline) from each mouse. Dashed boxes indicate the two mice displayed in A-K.

\section{Extrinsic inputs to eSCNs and iSCNs}

We found that eSCNs receive a greater number and a more diverse set of extrinsic inputs than iSCNs, even after accounting for the fact that eSCNs are more numerous than iSCNs. Strikingly, we observed much stronger projections to eSCNs than iSCNs, both across the brain (eSCN projection strength: $15.46 \pm 6.56$ [median \pm median absolute deviation], $\mathrm{n}=4$ mice; iSCN projection strength: $0.73 \pm 0.59$ [median \pm median absolute deviation], $\mathrm{n}=6$ mice; Wilcoxon rank sum test [one-tailed], $\mathrm{p}<0.005$; Fig. 2A; Fig. 3B), and within individual brain areas (Fig. 2B-K; Fig. 3A-B). With respect to individual brain areas, 36.73\% (18/49) were found to send significantly stronger projections to eSCNs than iSCNs (Wilcoxon rank sum test [one-tailed]; $p<$ 0.05; Fig. 3A). We also found that eSCNs tend to receive more inputs than iSCNs when input areas are grouped 

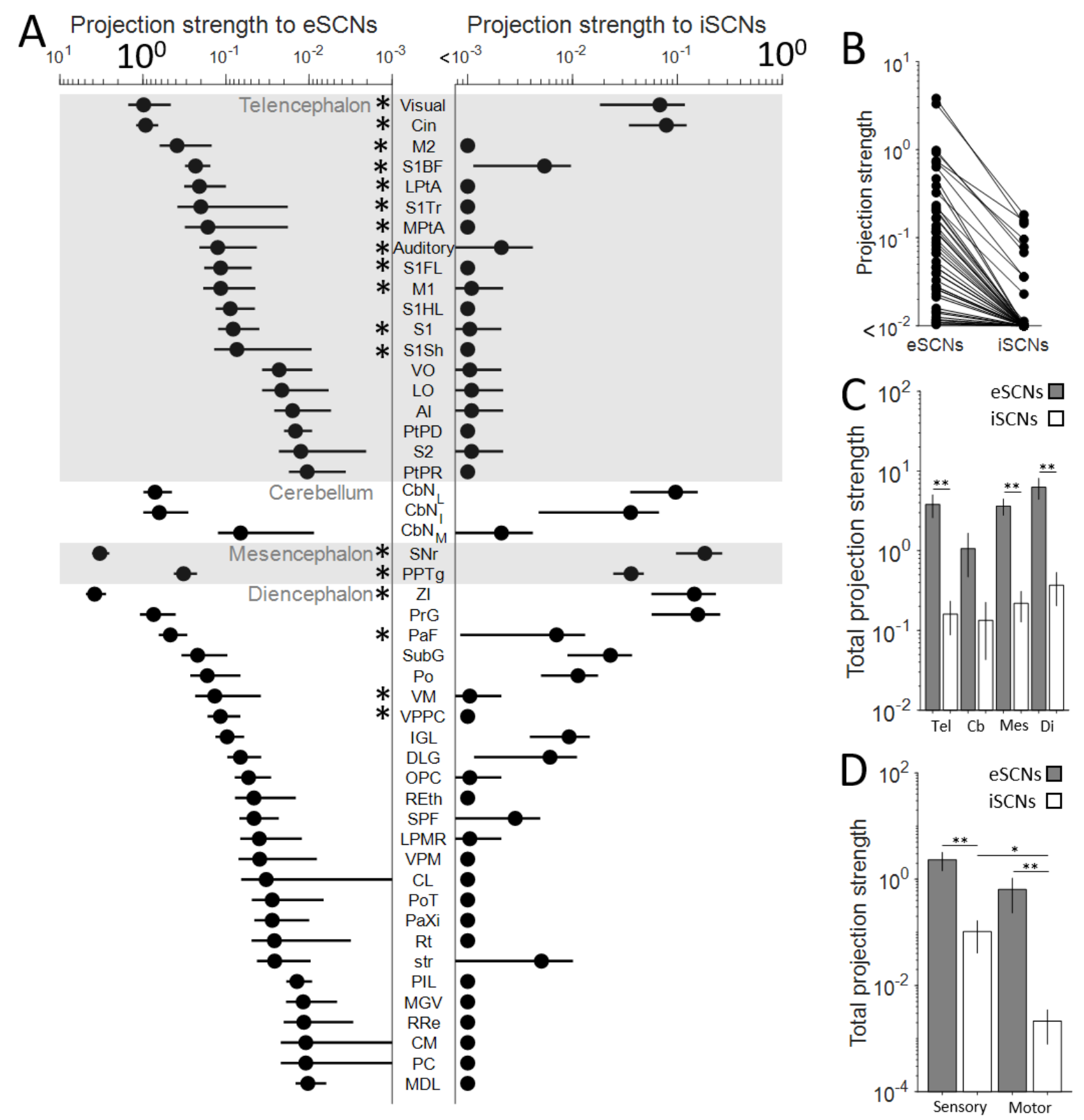

Figure 3. Projection strength to eSCNs and iSCNs

(A) Projection strength to eSCNs (left) and iSCNs (right) for each brain area. Note eSCNs and iSCNs are plotted on different scales for visibility. (B) Direct comparison between projection strength to eSCNs and iSCNs, shown on the same scale. (C) Total projection strength to eSCNs and iSCNs from developmentally defined brain regions. Tel (telencephalon); Cb (cerebellum); Mes (mesencephalon); Di (Diencephalon). (D) Total projection strength to eSCNs and iSCNs from regions of cortex and thalamus grouped according to sensory or motor function. Mean \pm SEM (eSCNs: $\mathrm{n}=4$ mice; iSCNs: $\mathrm{n}=6$ mice). $*: \mathrm{p}<0.05 ; * *: \mathrm{p}<0.01$.

by developmentally-defined categories of telencephalon, diencephalon, mesencephalon, and cerebellum

(Wilcoxon rank sum test [one-tailed]; $\mathrm{p}<0.01 ; \mathrm{n}=4$ mice [eSCNs]; $\mathrm{n}=6$ mice [iSCNs]; Fig. 3C).

eSCNs and iSCNs tended to receive their strongest projections from the same brain areas. The areas

with the most prominent projections to the $\mathrm{SC}_{\mathrm{id}}$ were zona incerta and $\mathrm{SNr}$, although inputs from the 
pregeniculate nucleus of the prethalamus made up a substantial proportion (12\%) of all inputs to iSCNs (Fig.

3A). Additionally, eSCNs and iSCNs both received their strongest cortical projections from visual and cingulate cortex and their strongest cerebellar projections from lateral and intermediate cerebellar nuclei (Fig. 3A).

Interestingly, when we classified cortical or thalamic brain areas as "sensory" or "motor" (Watson et al., 2012) we found that iSCNs were targeted by sensory areas more than motor areas (Wilcoxon signed rank test [two-tailed]; $\mathrm{n}=6$ mice; $\mathrm{p}=0.0313$; Fig. 3D); however, this was not true of eSCNs (Wilcoxon signed rank test [two-tailed]; $\mathrm{n}=4$ mice; $\mathrm{p}=0.125$

Fig. 3D). Taken together, these results suggest that eSCNs and iSCNs receive their strongest inputs from a similar set of brain areas, but that eSCNs receive a greater number and more diverse set of inputs overall.

\section{Laterality of inputs to eSCNs and} $i S C N s$

Consistent with previous findings (Sparks and HartwichYoung, 1989), the $\mathrm{SC}_{\mathrm{id}}$ exhibited much stronger ipsilateral than contralateral input from most brain regions (Fig. 4; see Materials and Methods). Cerebellotectal projections deviated from this

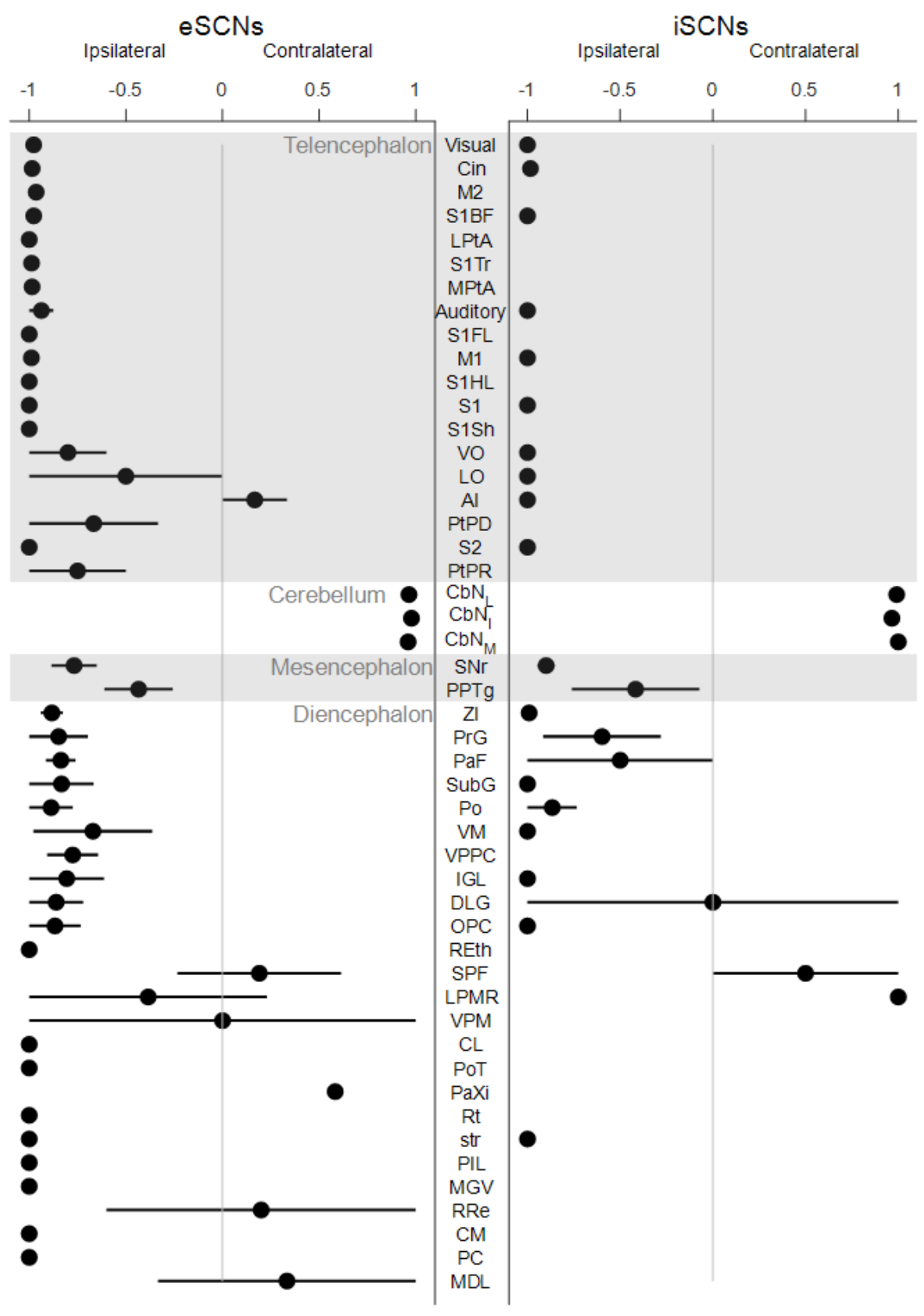

Figure 4. Laterality of SC inputs Laterality preference to eSCNs (left) and iSCNs (right) for each brain area. Areas ordered as in Figure 3. Mean \pm SEM (eSCNs: $n=4$ mice; iSCNs: $n=6$ mice). 
pattern, which is consistent with the well-established robust interconnectivity of the cerebellum with the contralateral side of the brain. The ipsilateral preferences from other areas were most strongly observed in inputs to iSCNs; however, input preference to eSCNs, specifically from cortical and thalamic areas, ranged from strongly ipsilateral to weakly contralateral (Fig. 4). For example, inputs to eSCNs from primary somatosensory cortex were almost entirely ipsilateral, while eSCN inputs from agranular insular cortex had a mild contralateral preference. Our observations indicate that overall, eSCNs receive more bilateral input than iSCNs, suggesting that eSCNs may be more involved in integrating sensory inputs from both sides of the body, while iSCNs may process more exclusively ipsilateral input.

\section{Relationship between projection strength and rostrocaudal position of starter neurons}

The $\mathrm{SC}_{\mathrm{id}}$ has a well-

characterized topographic

organization along its

rostrocaudal axis, with

small orienting movements

encoded rostrally, and

larger orienting movements

represented caudally

(Sahibzada et al., 1986;

Gandhi and Katnani, 2011).

We therefore examined the

extent to which input

neuron pattern depended

upon the rostrocaudal

position of starter neurons
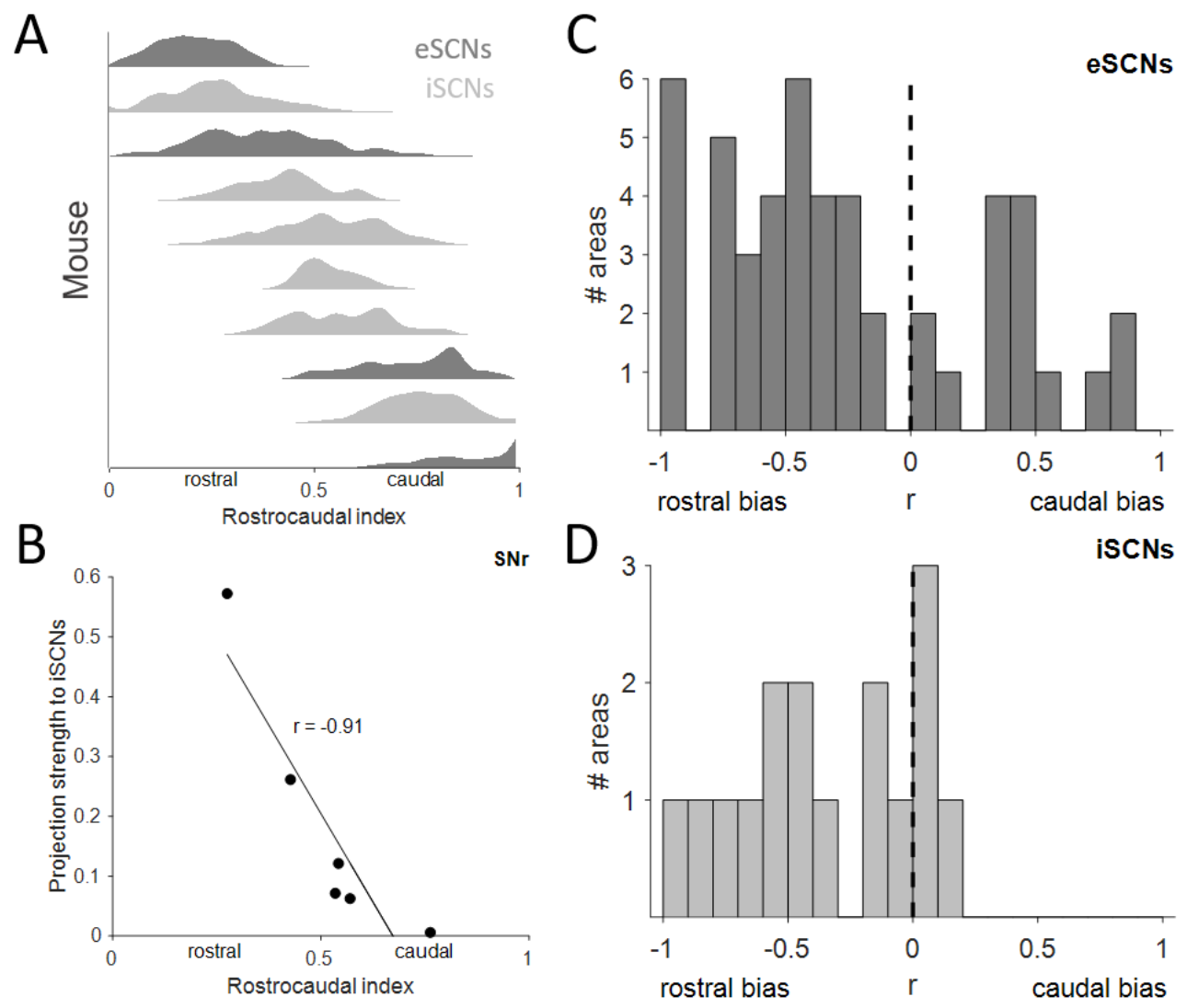

Figure 5. Extrinsic inputs favor the rostral SC

(A) Normalized rostrocaudal position of the starter neuron population for each mouse. (B) Pearson's correlation between mean rostrocaudal position of starter neurons and projection strength from $\mathrm{SNr}$ to iSCNs. (C, D) Correlation coefficients relating mean projection strength to rostrocaudal index of injection, as in B, for all areas: eSCNs (C); iSCNs (D). Dashed line at $\mathrm{x}=0$ indicates no rostrocaudal bias.

within the $\mathrm{SC}_{\mathrm{id}}$. Across mice, we labeled both eSCNs and iSCNs at several points along the rostrocaudal axis 
(Fig. 5A). We observed a tendency across areas for stronger projection strengths to be associated with more rostrally located starter neurons: (eSCN: median Pearson Correlation Coefficient $\mathrm{r}=-0.36, \mathrm{p}=0.0024, \mathrm{n}=49$ brain areas [Wilcoxon signed rank test]; iSCN median Pearson Correlation Coefficient $r=-0.41, p=0.0044, n$ $=16$ brain areas [Wilcoxon signed rank test]; Fig. 5C, D). This trend was observed in both cell types. Overall, these findings indicate that $\mathrm{eSCNs}$ and iSCNs toward the rostral pole of the $\mathrm{SC}_{\mathrm{id}}$ receive moderately more inputs than their caudal counterparts.

\section{Extrinsic inputs to subset of tectofugal eSCNs}

eSCNs comprise about

$70 \%$ of $\mathrm{SC}_{\mathrm{id}}$ neurons (Mize,

1992) and are diverse with

respect to morphology and

projection patterns (Pettit et

al., 1999; Isa and Hall, 2009;

Sooksawate et al., 2011;

Ghitani et al., 2014). As a first

step toward identifying

patterns of inputs to putative

subclasses of eSCNs, we

focused on inputs to crossed
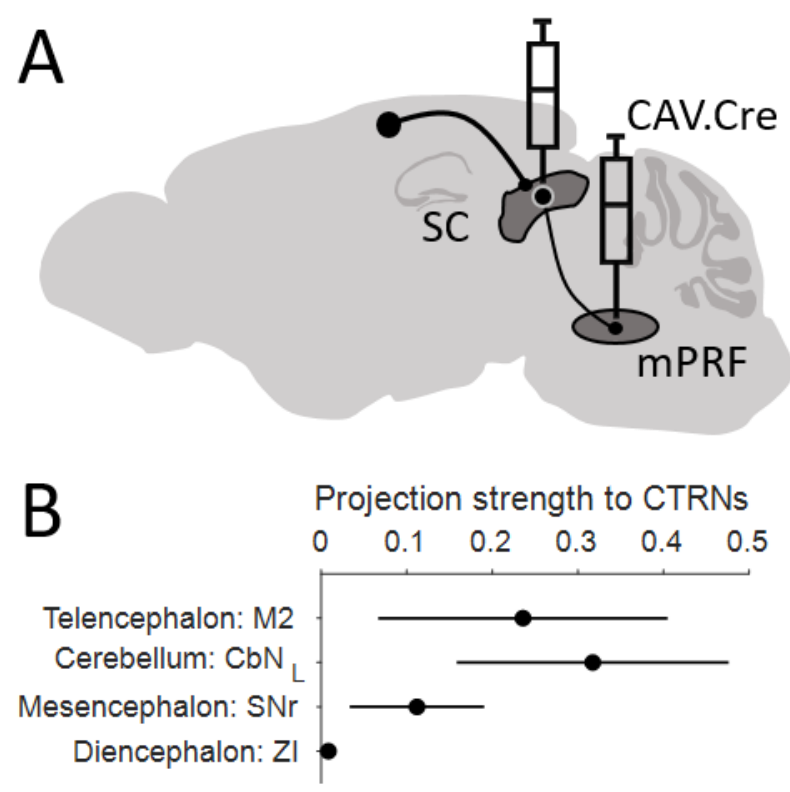

Figure 6: CTRNs receive fewer inputs than eSCNs

Experimental strategy targeting CTRNs. (B) Projection strength from areas targeting CTRNs. Mean \pm SEM ( $n=2$ mice). (C) Projection strength to eSCNs vs. CTRNs. Mean \pm SEM (eSCNs: $\mathrm{n}=4$ mice; CTRNs: $\mathrm{n}=2$ mice).

tecto-reticular neurons ("CTRNs") which are thought to be critical drivers of orienting movements and have been characterized in slice experiments (Sooksawate et al., 2005, 2008). We combined our Cre-dependent rabies trans-complementation approach with a retrograde Cre virus (Peltékian et al., 2002) injection into the contralateral MPRF of wild-type mice (see Materials and Methods; Fig 6A), such that starter neurons would be limited to MPRF-projecting $\mathrm{SC}_{\mathrm{id}}$ neurons. We found that secondary motor cortex, the lateral cerebellar nuclei, $\mathrm{SNr}$, and zona incerta were the only areas that provided measurable input to CTRNs (Fig. 6B), and that eSCNs 
bioRxiv preprint doi: https://doi.org/10.1101/824250; this version posted October 30, 2019. The copyright holder for this preprint (which was not certified by peer review) is the author/funder. All rights reserved. No reuse allowed without permission.

received much stronger projections than CTRNs from these and other areas (Wilcoxon signed rank test [onetailed]; $\mathrm{p}<2 \times 10^{9} ; \mathrm{n}=49$ brain areas; Fig. 6C). There was no difference in the laterality preference to eSCNs and CTRNs. Together, these results indicate that, although CTRNs play a direct role in the orienting motor output function of the $\mathrm{SC}_{\mathrm{id}}$, they receive a smaller and less diverse set of extrinsic inputs than the general eSCN population.

\section{Layer-specific targeting of contralateral SC}

Commissural SC neurons are thought to play a role in coordinating activity between the two SCs (Takahashi et al., 2005, 2007, 2010). To broaden our understanding of these inter-SC projection patterns, we examined the cell-type-, layer- and, rostrocaudal-specificity of inputs from the contralateral SC. We found that eSCNs

\section{A Contra SC inputs to eSCNs}
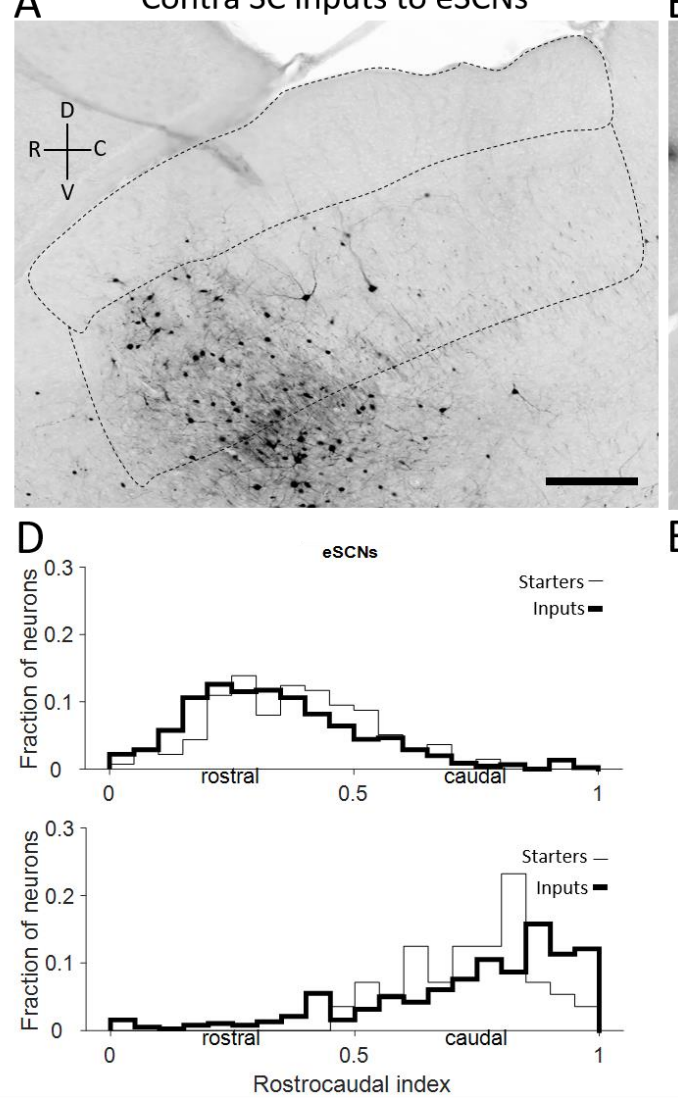

B

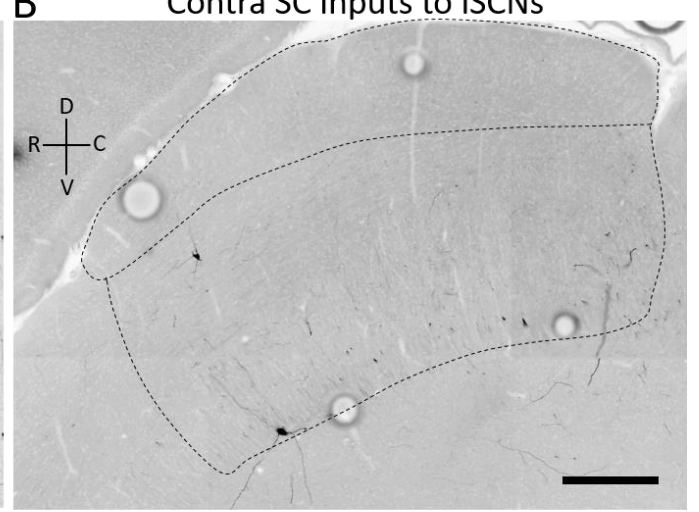

$\mathrm{E}$
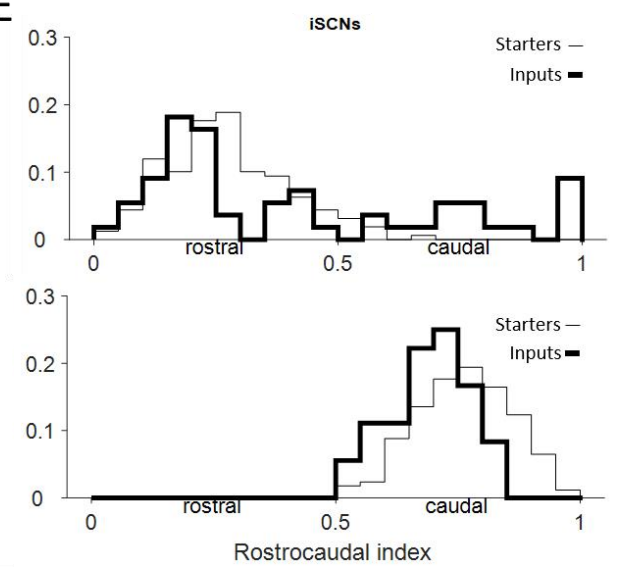

C
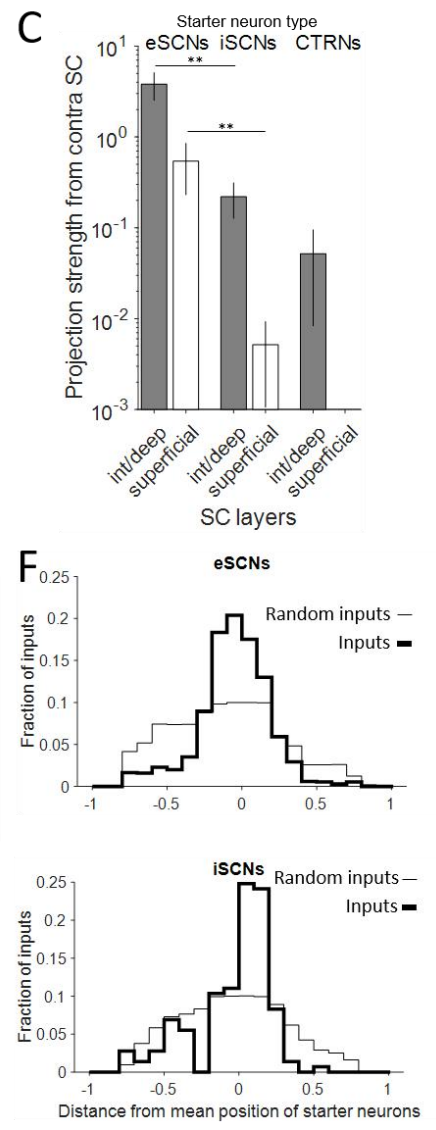

Figure 7: Layer-specific targeting of contralateral SC

(A-B) Contralateral SC inputs to eSCNs (A) or iSCNs (B). Dashed lines depict the borders of the superficial SC, $\mathrm{SC}_{\mathrm{id}}$, and underlying periaqueductal gray. (C) Projection strength from the contralateral $\mathrm{SC}_{\mathrm{id}}$ and superficial $\mathrm{SC}$ to eSCNs $(\mathrm{n}=4$ mice), iSCNs $\left(n=6\right.$ mice), and CTRNs ( $n=2$ mice). Mean $\pm S E M ; * *: p<0.01$. (D) Normalized rostrocaudal position of excitatory $S_{i d}$ starter and input neurons in the contralateral $\mathrm{SC}_{i d}$ for two Vglut2-Cre mice. (E) Same as in D except for inhibitory $\mathrm{SC}_{\text {id }}$ starter neurons in two Gad2-Cre mice. (F) Normalized rostrocaudal distance between input neurons and mean position of starter neurons in each mouse, compared to expected distance for randomly distributed input neurons. eSCNs (top): $\mathrm{n}=4$ mice; iSCNs (bottom): $\mathrm{n}=6$ mice. 
received more input from the contralateral $\mathrm{SC}_{\mathrm{id}}$, as well as the superficial $\mathrm{SC}$, than iSCNs (Wilcoxon rank sum test [one-tailed]; $\mathrm{n}=6$ mice $[\mathrm{eSCNs}] ; \mathrm{n}=4$ mice [iSCNs]; $\mathrm{SC}_{\mathrm{id}}: \mathrm{p}=0.0048$; superficial SC: $\mathrm{p}=0.0095 ;$ Fig. 7A-C). We also observed that the rostrocaudal position of contralateral $\mathrm{SC}_{\mathrm{id}}$ inputs mirrored the rostrocaudal position of starter neurons (Fig.7D-F), such that rostral poles of the two SCs were preferentially interconnected, as were caudal segments. Together, these results suggest that commissural SC neurons mainly target eSCNs located in analogous rostrocaudal positions.

\section{DISCUSSION}

The SC is critical for a wide range of functions, ranging from spatial attention to multisensory integration to adaptive behavioral responses (Dean et al., 1989; Stein and Stanford, 2008; Gandhi and Katnani, 2011; Krauzlis et al., 2013; Basso and May, 2017). Its intricate internal circuitry is organized into seven cytoarchitechtonically-defined layers composed of excitatory and inhibitory neurons each with diverse projection patterns (Edwards, 1977; Mize, 1992; Olivier et al., 1998, 2000; Pettit et al., 1999; Takahashi et al., 2005, 2007, 2010; Isa and Hall, 2009; Sooksawate et al., 2011; Ghitani et al., 2014). SC $\mathrm{id}$ computations are also influenced by the dense innervation from a network of brain structures involved in sensory and motor functions. While this complex anatomical arrangement presents challenges to identify subcircuits for putative SC functions, our study makes inroads into this challenge by employing monosynaptic tracing from identified neuronal subtypes within the $\mathrm{SC}_{\mathrm{id}}$ and identifies a number of thematic input patterns to the structure varying along a functional axis of rostrocaudal organization. We found that eSCNs received more inputs than iSCNs, extrinsic inputs to eSCNs and iSCNs had a rostral bias, CTRNs were targeted by many fewer brain areas than the general population of eSCNs, and populations of commissurally connected SC neurons were located in similar rostrocaudal positions. While our study has implications for the full range of $\mathrm{SC}_{\mathrm{id}}$ functions, we focus here on how our findings inform the contributions of the $\mathrm{SC}_{\mathrm{id}}$ to orienting movements and multisensory integration.

Orienting behaviors can be conceptualized as two discrete components: selecting a target from among multiple options and terminating a target-directed movement appropriately to acquire the target. While these 
functions are coordinated by computations performed within a network of interconnected brain areas, the dual maps of visual and movement space within the $\mathrm{SC}_{\mathrm{id}}$ make it a model system in which to study the components of orienting behavior. The superficial layers of the colliculus contain a map of visual space inherited from its direct retinal inputs, raising the question of whether the map of movement space contained within $\mathrm{SC}_{\mathrm{id}}$ similarly arises from the orderly arrangement of its inputs. For example, does the $\mathrm{SC}_{\mathrm{id}}$ receive movement commands from the superficial layers or from outside the SC which are then relayed to downstream motor structures, or do critical intrinsic processes within the $\mathrm{SC}_{\mathrm{id}}$ produce the map of movement space that ultimately determines the vector of the executed movement?

Our findings that different populations of SC neurons receive unique patterns of input argue against the view of the $\mathrm{SC}_{\mathrm{id}}$ as a simple relay and instead support the idea that intrinsic processing gives rise to $\mathrm{SC}_{\mathrm{id}}$ computations for orienting behavior. Studies examining $\mathrm{SC}_{\mathrm{id}}$ activity when multiple targets are present (Basso and Wurtz, 1997; McPeek and Keller, 2004; Li and Basso, 2005; Felsen and Mainen, 2008) support a model of $\mathrm{SC}_{\mathrm{id}}$ function whereby a "competition" takes place between two or more active foci within the colliculus (Basso and May, 2017). While this competition could simply reflect differences in the activity level of different inputs, local inhibitory connectivity within and between the two $\mathrm{SC}_{\mathrm{id}} \mathrm{S}$ (Takahashi et al., 2005, 2007, 2010; Isa and Hall, 2009; Sooksawate et al., 2011; Ghitani et al., 2014) suggests that active intrinsic $\mathrm{SC}_{\mathrm{id}}$ processes may be at work. Potential roles of inhibition include mediating the competition between multiple regions of $\mathrm{SC}_{\mathrm{id}}$ representing movement vectors to available targets and sharpening and refining the activity needed to acquire a chosen target. Our finding that iSCNs receive fewer inputs than eSCNs indicates that whichever processes they mediate, a smaller subset of inputs relative to eSCNs is used. Further, our observations that CTRNs receive far fewer inputs than the general population of eSCNs argues against the $\mathrm{SC}_{\mathrm{id}}$ acting as a relay, and instead suggests that these output neurons are likely sampling and transforming information processed within the SC. Indeed, CTRNs have been found to receive commissural inputs from both eSCNs and iSCNs (Takahashi et al., 2005, 2007, 2010). Thus, our findings support the view that the SC is a critical node in the network of interconnected brain regions responsible for spatial decision making. 
Target selection and acquisition are unique components of orienting behavior and are therefore likely to be modulated by distinct inputs. Target selection requires information pertaining to the relative position(s) of one or multiple targets in space, as well as predicted value(s) associated with each target, while acquiring a target will require information with both a high degree of spatiotemporal resolution and up-to-date information on the state of the effector(s) that will be used for acquiring the target. Notably, the strongest projections we observed arise from brain areas well-equipped to provide the various forms of information needed for both target selection and acquisition. Visual, auditory, and barrel cortex are among the regions projecting most strongly to the $\mathrm{SC}_{\mathrm{id}}$ (Fig. 3) and are likely important for localizing potential targets in space, while the $\mathrm{SNr}$ sends a robust inhibitory projection (Graybiel and Ragsdale, 1979), which likely conveys the necessary values associated with individual targets that are required to select among them (Handel and Glimcher, 2000; Basso and Wurtz, 2002; Sato and Hikosaka, 2002; Bryden et al., 2011). Additionally, cerebellar projections to the $\mathrm{SC}_{\mathrm{id}}$ may be critical in conveying predictive information regarding the position of effectors throughout the trajectory of the movement (Ohyama et al., 2003; Shadmehr, 2017; Owens et al., 2018; Becker and Person, 2019), ultimately mediating successful target acquisition. Indeed, studies performing muscimol inactivation of the cFN in monkeys making saccades to visual targets concluded that cerebellotectal projections might provide the $\mathrm{SC}_{\mathrm{id}}$ with information about the displacement needed to acquire spatial targets (Goffart et al., 1998). In addition to cerebellar inputs to the $\mathrm{SC}_{\mathrm{id}}$, our finding that $\mathrm{eSCN}$ and iSCN inputs tend to favor the rostral pole of the $\mathrm{SC}_{\mathrm{id}}$ is also likely to play a role in mediating the small movements required for target acquisition.

The observation that eSCNs receive more inputs than iSCNs suggests that they may also receive a higher degree of convergent inputs, which has implications for how the $\mathrm{SC}_{\mathrm{id}}$ might process behaviorally relevant multisensory information. Previous work has shown that $\mathrm{SC}_{\mathrm{id}}$ neurons receive convergent visual, auditory, and somatosensory input (Meredith and Stein, 1986). These multisensory inputs synergistically drive $\mathrm{SC}_{\mathrm{id}}$ spike output (Miller et al., 2015), which is thought to underlie the saliency of biologically relevant stimuli, allowing animals to produce appropriate orienting responses (Stein and Stanford, 2008; Stein et al., 2014). Modeling work suggests that the supralinear response to multisensory information is attributable to local 
inhibitory input (Miller et al., 2015). Thus, our observation that iSCNs receive far fewer inputs than eSCNs, and are therefore also less likely to receive convergent multisensory information, allows us to imagine a system whereby fast-spiking iSCNs (Sooksawate et al., 2011) receiving unisensory information contribute to the multisensory enhancement of eSCNs via a local disinhibitory mechanism.

This study has extended our knowledge of $\mathrm{SC}_{\mathrm{id}}$ inputs and has critically elucidated their cell-type targeting. While technique-specific caveats exist, they do not clearly challenge our interpretations. First, while G-deleted rabies virus-mediated monosynaptic tracing is a powerful tool capable of labeling direct inputs to populations of genetically defined neurons (Wickersham et al., 2007; Callaway and Luo, 2015; Luo et al., 2018), the transmission efficiency can vary based on the molecular composition of presynaptic proteins (Callaway and Luo, 2015). This should be considered when comparing projection strengths across different brain areas. However, since the transmission efficiency is thought to be affected minimally by differences in the cell-type from which the virus is "jumping", this caveat does not affect our findings that eSCNs receive more inputs than iSCNs and CTRNs, that there is a rostral bias of inputs to eSCNs and iSCNs, or that commissurally connected SC neurons are located in similar rostrocaudal positions.

There are several potential avenues through which future studies can build upon our findings. For example, learning-dependent developmental changes in synaptic connectivity can be examined by combining monosynaptic rabies tracing with a behavioral approach in juvenile mice. Previous work in owls showing that corrupted visual information leads to a topographical misalignment of auditory and visual information within the OT (Brainard and Knudsen, 1998) suggests that task-relevant changes in $\mathrm{SC}_{\text {id }}$ connectivity might take place during learning. Additionally, similar to the rostrocaudal organization of the $\mathrm{SC}_{\mathrm{id}}$ map of movement space, there is a mediolateral organization that governs approach vs. avoidance behaviors (Dean et al., 1986, 1989; Sahibzada et al., 1986). While we did not address this in our study, future experiments may wish to examine the extent to which these areas receive unique or overlapping inputs. Finally, the behavioral role of specific inputs to the $\mathrm{SC}_{\mathrm{id}}$ can be examined by using a self-inactivating rabies virus (Ciabatti et al., 2017) to transport a calcium indicator (Osakada et al., 2011) to reveal input-specific population level neuronal activity during task performance. 


\section{LITERATURE CITED}

Angaut P. 1969. The fastigio-tectal projections. An anatomical experimental study. Brain Research 13:186-189.

Apter JT. 1945. Projection of the retina on superior colliculus of cats. Journal of Neurophysiology 8:123-134.

Basso MA, May PJ. 2017. Circuits for Action and Cognition: A View from the Superior Colliculus. Annual Review of Vision Science 3:197-226.

Basso MA, Wurtz RH. 1997. Modulation of neuronal activity by target uncertainty. Nature 389:66-69.

Basso MA, Wurtz RH. 2002. Neuronal Activity in Substantia Nigra Pars Reticulata during Target Selection. J Neurosci 22:1883-1894.

Batton RR, Jayaraman A, Ruggiero D, Carpenter MB. 1977. Fastigial efferent projections in the monkey: An autoradiographic study. Journal of Comparative Neurology 174:281-305.

Becker MI, Person AL. 2019. Cerebellar Control of Reach Kinematics for Endpoint Precision. Neuron [Internet]. Available from: http://www.sciencedirect.com/science/article/pii/S0896627319304325

Beitzel CS, Houck BD, Lewis SM, Person AL. 2017. Rubrocerebellar Feedback Loop Isolates the Interposed Nucleus as an Independent Processor of Corollary Discharge Information in Mice. J Neurosci 37:10085-10096.

Brainard MS, Knudsen El. 1998. Sensitive Periods for Visual Calibration of the Auditory Space Map in the Barn Owl Optic Tectum. J Neurosci 18:3929-3942.

Branda CS, Dymecki SM. 2004. Talking about a revolution: The impact of site-specific recombinases on genetic analyses in mice. Developmental cell 6:7-28.

Bryden DW, Johnson EE, Diao X, Roesch MR. 2011. Impact of expected value on neural activity in rat substantia nigra pars reticulata. Eur J Neurosci 33:2308-2317.

Callaway EM, Luo L. 2015. Monosynaptic Circuit Tracing with Glycoprotein-Deleted Rabies Viruses. J Neurosci 35:89798985.

Ciabatti E, González-Rueda A, Mariotti L, Morgese F, Tripodi M. 2017. Life-Long Genetic and Functional Access to Neural Circuits Using Self-Inactivating Rabies Virus. Cell 170:382-392.e14.

Corneil BD, Olivier E, Munoz DP. 2002. Neck Muscle Responses to Stimulation of Monkey Superior Colliculus. II. Gaze Shift Initiation and Volitional Head Movements. Journal of Neurophysiology 88:2000-2018.

Courjon J-H, Olivier E, Pélisson D. 2004. Direct evidence for the contribution of the superior colliculus in the control of visually guided reaching movements in the cat. The Journal of Physiology 556:675-681.

Courjon J-H, Zénon A, Clément G, Urquizar C, Olivier E, Pélisson D. 2015. Electrical stimulation of the superior colliculus induces non-topographically organized perturbation of reaching movements in cats. Front Syst Neurosci [Internet] 9. Available from: https://www.frontiersin.org/articles/10.3389/fnsys.2015.00109/full

Dean P, Redgrave P, Sahibzada N, Tsuji K. 1986. Head and body movements produced by electrical stimulation of superior colliculus in rats: Effects of interruption of crossed tectoreticulospinal pathway. Neuroscience 19:367380.

Dean P, Redgrave P, Westby GWM. 1989. Event or emergency? Two response systems in the mammalian superior colliculus. Trends in Neurosciences 12:137-147. 
Duan CA, Pan Y, Ma G, Zhou T, Zhang S, Xu N. 2019. A cortico-collicular pathway for motor planning in a memorydependent perceptual decision task. bioRxiv:709170.

Edelstein A, Amodaj N, Hoover K, Vale R, Stuurman N. 2010. Computer Control of Microscopes Using $\mu$ Manager. Current Protocols in Molecular Biology 92:14.20.1-14.20.17.

Edelstein AD, Tsuchida MA, Amodaj N, Pinkard H, Vale RD, Stuurman N. 2014. Advanced methods of microscope control using $\mu$ Manager software. Journal of Biological Methods 1:e10.

Edwards SB. 1977. The commissural projection of the superior colliculus in the cat. J Comp Neurol 173:23-40.

Edwards SB, Ginsburgh CL, Henkel CK, Stein BE. 1979. Sources of subcortical projections to the superior colliculus in the cat. Journal of Comparative Neurology 184:309-329.

Edwards SB, Rosenquist AC, Palmer LA. 1974. An autoradiographic study of ventral lateral geniculate projections in the cat. Brain Research 72:282-287.

Felsen G, Mainen ZF. 2008. Neural Substrates of Sensory-Guided Locomotor Decisions in the Rat Superior Colliculus. Neuron 60:137-148.

Freedman EG, Stanford TR, Sparks DL. 1996. Combined eye-head gaze shifts produced by electrical stimulation of the superior colliculus in rhesus monkeys. Journal of Neurophysiology 76:927-952.

Fries W. 1984. Cortical projections to the superior colliculus in the macaque monkey: A retrograde study using horseradish peroxidase. Journal of Comparative Neurology 230:55-76.

Gandhi NJ, Katnani HA. 2011. Motor Functions of the Superior Colliculus. Annu Rev Neurosci 34:205-231.

Garey L, Jones EG, Powell TP. 1968. Interrelationships of striate and extrastriate cortex with the primary relay sites of the visual pathway. Journal of Neurology, Neurosurgery \& Psychiatry 31:135-157.

Ghitani N, Bayguinov PO, Vokoun CR, McMahon S, Jackson MB, Basso MA. 2014. Excitatory Synaptic Feedback from the Motor Layer to the Sensory Layers of the Superior Colliculus. J Neurosci 34:6822-6833.

Goffart L, Pélisson D, Guillaume A. 1998. Orienting Gaze Shifts During Muscimol Inactivation of Caudal Fastigial Nucleus in the Cat. II. Dynamics and Eye-Head Coupling. Journal of Neurophysiology 79:1959-1976.

Goldberg ME, Wurtz RH. 1972a. Activity of superior colliculus in behaving monkey. I. Visual receptive fields of single neurons. Journal of Neurophysiology 35:542-559.

Goldberg ME, Wurtz RH. 1972b. Activity of superior colliculus in behaving monkey. II. Effect of attention on neuronal responses. J Neurophysiol 35:560-574.

Graybiel AM. 1974. Visuo-cerebellar and cerebello-visual connections involving the ventral lateral geniculate nucleus. Exp Brain Res 20:303-306.

Graybiel AM, Ragsdale CW. 1979. Fiber connections of the basal ganglia. Prog Brain Res 51:237-283.

Grofová I, Ottersen OP, Rinvik E. 1978. Mesencephalic and diencephalic afferents to the superior colliculus and periaqueductal gray substance demonstrated by retrograde axonal transport of horseradish peroxidase in the cat. Brain Research 146:205-220. 
Guillaume A, Pélisson D. 2001. Gaze shifts evoked by electrical stimulation of the superior colliculus in the headunrestrained cat. II. Effect of muscimol inactivation of the caudal fastigial nucleus. European Journal of Neuroscience 14:1345-1359.

Handel A, Glimcher PW. 2000. Contextual Modulation of Substantia Nigra Pars Reticulata Neurons. Journal of Neurophysiology 83:3042-3048.

Hanes DP, Wurtz RH. 2001. Interaction of the Frontal Eye Field and Superior Colliculus for Saccade Generation. Journal of Neurophysiology 85:804-815.

Herrero L, Rodríguez F, Salas C, Torres B. 1998. Tail and eye movements evoked by electrical microstimulation of the optic tectum in goldfish. Exp Brain Res 120:291-305.

Hopkins DA, Niessen LW. 1976. Substantia nigra projections to the reticular formation, superior colliculus and central gray in the rat, cat and monkey. Neuroscience Letters 2:253-259.

Huerta MF, Harting JK. 1982. Tectal control of spinal cord activity: neuroanatomical demonstration of pathways connecting the superior colliculus with the cervical spinal cord grey. Prog Brain Res 57:293-328.

Isa T, Hall WC. 2009. Exploring the Superior Colliculus In Vitro. Journal of Neurophysiology 102:2581-2593.

Isa T, Sasaki S. 2002. Brainstem control of head movements during orienting; organization of the premotor circuits. Progress in Neurobiology 66:205-241.

Kawamura S, Hattori S, Higo S, Matsuyama T. 1982. The cerebellar projections to the superior colliculus and pretectum in the cat: An autoradiographic and horseradish peroxidase study. Neuroscience 7:1673-1689.

Kawamura S, Sprague JM, Niimi K. 1974. Corticofugal projections from the visual cortices to the thalamus, pretectum and superior colliculus in the cat. Journal of Comparative Neurology 158:339-362.

Kim EJ, Jacobs MW, Ito-Cole T, Callaway EM. 2016. Improved Monosynaptic Neural Circuit Tracing Using Engineered Rabies Virus Glycoproteins. Cell Rep 15:692-699.

Krauzlis RJ, Lovejoy LP, Zénon A. 2013. Superior Colliculus and Visual Spatial Attention. Annual Review of Neuroscience 36:165-182.

du Lac S, Knudsen El. 1991. Early visual deprivation results in a degraded motor map in the optic tectum of barn owls. Proc Natl Acad Sci U S A 88:3426-3430.

Lee C, Rohrer WH, Sparks DL. 1988. Population coding of saccadic eye movements by neurons in the superior colliculus. Nature 332:357-360.

Li X, Basso MA. 2005. Competitive stimulus interactions within single response fields of superior colliculus neurons. J Neurosci 25:11357-11373.

Liang F, Xiong XR, Zingg B, Ji X, Zhang LI, Tao HW. 2015. Sensory Cortical Control of a Visually Induced Arrest Behavior via Corticotectal Projections. Neuron 86:755-767.

Luo L, Callaway EM, Svoboda K. 2018. Genetic Dissection of Neural Circuits: A Decade of Progress. Neuron 98:865.

Masullo L, Mariotti L, Alexandre N, Freire-Pritchett P, Boulanger J, Tripodi M. 2019. Genetically Defined Functional Modules for Spatial Orienting in the Mouse Superior Colliculus. Curr Biol 29:2892-2904.e8. 
McPeek RM, Keller EL. 2004. Deficits in saccade target selection after inactivation of superior colliculus. Nat Neurosci 7:757-763.

Meredith MA, Stein BE. 1986. Visual, auditory, and somatosensory convergence on cells in superior colliculus results in multisensory integration. Journal of Neurophysiology 56:640-662.

Meyer RL, Sperry RW. 1973. Tests for neuroplasticity in the anuran retinotectal system. Experimental Neurology 40:525539.

Miller RL, Pluta SR, Stein BE, Rowland BA. 2015. Relative Unisensory Strength and Timing Predict Their Multisensory Product. J Neurosci 35:5213-5220.

Mize RR. 1992. The organization of GABAergic neurons in the mammalian superior colliculus. Prog Brain Res 90:219-248.

Ohyama T, Nores WL, Murphy M, Mauk MD. 2003. What the cerebellum computes. Trends in Neurosciences 26:222227.

Oliveira AF, Yonehara K. 2018. The Mouse Superior Colliculus as a Model System for Investigating Cell Type-Based Mechanisms of Visual Motor Transformation. Front Neural Circuits [Internet] 12. Available from: https://www.ncbi.nlm.nih.gov/pmc/articles/PMC6094993/

Olivier E, Corvisier J, Pauluis Q, Hardy O. 2000. Evidence for glutamatergic tectotectal neurons in the cat superior colliculus: a comparison with GABAergic tectotectal neurons: Glutamatergic tectotectal neurons. European Journal of Neuroscience 12:2354-2366.

Olivier E, Porter JD, May PJ. 1998. Comparison of the distribution and somatodendritic morphology of tectotectal neurons in the cat and monkey. Vis Neurosci 15:903-922.

Osakada F, Mori T, Cetin AH, Marshel JH, Virgen B, Callaway EM. 2011. New rabies virus variants for monitoring and manipulating activity and gene expression in defined neural circuits. Neuron 71:617-631.

Owens CB, de Boer C, Gennari G, Broersen R, Pel JJ, Miller B, Clapp W, van der Werf YD, De Zeeuw Cl. 2018. Early Trajectory Prediction in Elite Athletes. Cerebellum 17:766-776.

Paré M, Wurtz RH. 2001. Progression in Neuronal Processing for Saccadic Eye Movements From Parietal Cortex Area LIP to Superior Colliculus. Journal of Neurophysiology 85:2545-2562.

Paxinos G, Franklin KBJ. (2013). The mouse brain in steriotaxic coordinates. (4th Ed.). London, UK: Elsevier Inc.

Peltékian E, Garcia L, Danos O. 2002. Neurotropism and retrograde axonal transport of a canine adenoviral vector: a tool for targeting key structures undergoing neurodegenerative processes. Mol Ther 5:25-32.

Peng T, Thorn K, Schroeder T, Wang L, Theis FJ, Marr C, Navab N. 2017. A BaSiC tool for background and shading correction of optical microscopy images. Nat Commun 8:14836.

Pettit DL, Helms MC, Lee P, Augustine GJ, Hall WC. 1999. Local Excitatory Circuits in the Intermediate Gray Layer of the Superior Colliculus. Journal of Neurophysiology 81:1424-1427.

Philipp R, Hoffmann K-P. 2014. Arm Movements Induced by Electrical Microstimulation in the Superior Colliculus of the Macaque Monkey. J Neurosci 34:3350-3363.

Redgrave P, Dean P, Westby GWM. 1990. Organization of the crossed tecto-reticulo-spinal projection in rat-I. Anatomical evidence for separate output channels to the periabducens area and caudal medulla. Neuroscience 37:571-584. 
Robinson DA. 1972. Eye movements evoked by collicular stimulation in the alert monkey. Vision Research 12:17951808.

Rueden CT, Schindelin J, Hiner MC, DeZonia BE, Walter AE, Arena ET, Eliceiri KW. 2017. ImageJ2: ImageJ for the next generation of scientific image data. BMC Bioinformatics 18:529.

Sahibzada N, Dean P, Redgrave P. 1986. Movements resembling orientation or avoidance elicited by electrical stimulation of the superior colliculus in rats. J Neurosci 6:723-733.

Sato M, Hikosaka O. 2002. Role of Primate Substantia Nigra Pars Reticulata in Reward-Oriented Saccadic Eye Movement. J Neurosci 22:2363-2373.

Schiller PH, True SD, Conway JL. 1980. Deficits in eye movements following frontal eye-field and superior colliculus ablations. Journal of Neurophysiology 44:1175-1189.

Schindelin J, Arganda-Carreras I, Frise E, Kaynig V, Longair M, Pietzsch T, Preibisch S, Rueden C, Saalfeld S, Schmid B, Tinevez J-Y, White DJ, Hartenstein V, Eliceiri K, Tomancak P, Cardona A. 2012. Fiji: an open-source platform for biological-image analysis. Nat Methods 9:676-682.

Segraves MA, Goldberg ME. 1987. Functional properties of corticotectal neurons in the monkey's frontal eye field. Journal of Neurophysiology 58:1387-1419.

Shadmehr R. 2017. Learning to Predict and Control the Physics of Our Movements. J Neurosci 37:1663-1671.

Sommer MA, Wurtz RH. 2000. Composition and Topographic Organization of Signals Sent From the Frontal Eye Field to the Superior Colliculus. Journal of Neurophysiology 83:1979-2001.

Sommer MA, Wurtz RH. 2001. Frontal Eye Field Sends Delay Activity Related to Movement, Memory, and Vision to the Superior Colliculus. Journal of Neurophysiology 85:1673-1685.

Sooksawate T, Isa K, Behan M, Yanagawa Y, Isa T. 2011. Organization of GABAergic inhibition in the motor output layer of the superior colliculus. European Journal of Neuroscience 33:421-432.

Sooksawate T, Isa K, Isa T. 2008. Cholinergic Responses in Crossed Tecto-Reticular Neurons of Rat Superior Colliculus. Journal of Neurophysiology 100:2702-2711.

Sooksawate T, Saito Y, Isa T. 2005. Electrophysiological and morphological properties of identified crossed tecto-reticular neurons in the rat superior colliculus. Neuroscience Research 52:174-184.

Sparks DL. 1999. Conceptual issues related to the role of the superior colliculus in the control of gaze. Current Opinion in Neurobiology 9:698-707.

Sparks DL, Hartwich-Young R. 1989. The deep layers of the superior colliculus. Rev Oculomot Res 3:213-255.

Stein BE, Stanford TR. 2008. Multisensory integration: current issues from the perspective of the single neuron. Nat Rev Neurosci 9:255-266.

Stein BE, Stanford TR, Rowland BA. 2014. Development of multisensory integration from the perspective of the individual neuron. Nat Rev Neurosci 15:520-535.

Steinmetz NA, Zatka-Haas P, Carandini M, Harris KD. 2018. Distributed correlates of visually-guided behavior across the mouse brain. bioRxiv:474437. 
Stubblefield EA, Costabile JD, Felsen G. 2013. Optogenetic investigation of the role of the superior colliculus in orienting movements. Behavioural Brain Research 255:55-63.

Sun Y, Nguyen AQ, Nguyen JP, Le L, Saur D, Choi J, Callaway EM, Xu X. 2014. Cell-Type-Specific Circuit Connectivity of Hippocampal CA1 Revealed through Cre-Dependent Rabies Tracing. Cell Reports 7:269-280.

Takahashi M, Sugiuchi Y, Izawa Y, Shinoda Y. 2005. Commissural Excitation and Inhibition by the Superior Colliculus in Tectoreticular Neurons Projecting to Omnipause Neuron and Inhibitory Burst Neuron Regions. Journal of Neurophysiology 94:1707-1726.

Takahashi M, Sugiuchi Y, Shinoda Y. 2007. Commissural Mirror-Symmetric Excitation and Reciprocal Inhibition Between the Two Superior Colliculi and Their Roles in Vertical and Horizontal Eye Movements. Journal of Neurophysiology 98:2664-2682.

Takahashi M, Sugiuchi Y, Shinoda Y. 2010. Topographic Organization of Excitatory and Inhibitory Commissural Connections in the Superior Colliculi and Their Functional Roles in Saccade Generation. Journal of Neurophysiology 104:3146-3167.

Taniguchi H, He M, Wu P, Kim S, Paik R, Sugino K, Kvitsani D, Fu Y, Lu J, Lin Y, Miyoshi G, Shima Y, Fishell G, Nelson SB, Huang ZJ. 2011. A Resource of Cre Driver Lines for Genetic Targeting of GABAergic Neurons in Cerebral Cortex. Neuron 71:995-1013.

Valentine DE, Sinha SR, Moss CF. 2002. Orienting responses and vocalizations produced by microstimulation in the superior colliculus of the echolocating bat, Eptesicus fuscus. J Comp Physiol A 188:89-108.

Vong L, Ye C, Yang Z, Choi B, Chua S, Lowell BB. 2011. Leptin Action on GABAergic Neurons Prevents Obesity and Reduces Inhibitory Tone to POMC Neurons. Neuron 71:142-154.

Wall NR, Wickersham IR, Cetin A, Parra MDL, Callaway EM. 2010. Monosynaptic circuit tracing in vivo through Credependent targeting and complementation of modified rabies virus. PNAS 107:21848-21853.

Walton MMG, Bechara B, Gandhi NJ. 2007. Role of the Primate Superior Colliculus in the Control of Head Movements. Journal of Neurophysiology 98:2022-2037.

Wang L, Liu M, Segraves MA, Cang J. 2015. Visual Experience Is Required for the Development of Eye Movement Maps in the Mouse Superior Colliculus. J Neurosci 35:12281-12286.

Watabe-Uchida M, Zhu L, Ogawa SK, Vamanrao A, Uchida N. 2012. Whole-Brain Mapping of Direct Inputs to Midbrain Dopamine Neurons. Neuron 74:858-873.

Watson C, Paxinos G, Puelles L. (2012). The Mouse Nervous System. London, UK: Elsevier Inc.

Werner W, Dannenberg S, Hoffmann K-P. 1997. Arm-movement-related neurons in the primate superior colliculus and underlying reticular formation: comparison of neuronal activity with EMGs of muscles of the shoulder, arm and trunk during reaching. Exp Brain Res 115:191-205.

Wickersham IR, Finke S, Conzelmann K-K, Callaway EM. 2007. Retrograde neuronal tracing with a deletion-mutant rabies virus. Nat Methods 4:47-49.

Wolf AB, Lintz MJ, Costabile JD, Thompson JA, Stubblefield EA, Felsen G. 2015. An integrative role for the superior colliculus in selecting targets for movements. Journal of Neurophysiology 114:2118-2131.

Wurtz RH, Goldberg ME. 1972. Activity of superior colliculus in behaving monkey. 3. Cells discharging before eye movements. Journal of Neurophysiology 35:575-586. 
bioRxiv preprint doi: https://doi.org/10.1101/824250; this version posted October 30, 2019. The copyright holder for this preprint (which was not certified by peer review) is the author/funder. All rights reserved. No reuse allowed without permission.

Wurtz RH, Sommer MA, Paré M, Ferraina S. 2001. Signal transformations from cerebral cortex to superior colliculus for the generation of saccades. Vision Research 41:3399-3412. 


\begin{tabular}{|c|c|}
\hline Al & Agranular insular cortex \\
\hline $\mathrm{CbN}_{1}$ & Cerebellar nuclei, interposed \\
\hline $\mathrm{CbN}_{\mathrm{L}}$ & Cerebellar nuclei, lateral \\
\hline $\mathrm{CbN}_{\mathrm{M}}$ & Cerebellar nuclei, medial \\
\hline Cin & Cingulate cortex \\
\hline $\mathrm{CL}$ & Centrolateral thalamic nucleus \\
\hline CM & Central medial thalamic nucleus \\
\hline DLG & Dorsal lateral geniculate nucleus \\
\hline IGL & Intergeniculate leaflet \\
\hline LO & Lateral orbital cortex \\
\hline LPMR & Lateral posterior thalamic nucleus, mediorostral \\
\hline LPtA & Lateral parietal association cortex \\
\hline M1 & Primary motor cortex \\
\hline M2 & Secondary motor cortex \\
\hline MDL & Mediodorsal thalamic nucleus, lateral \\
\hline MGV & Medial geniculate nucleus ventral \\
\hline MPtA & Medial parietal association cortex \\
\hline OPC & Oval paracentral thalamic nucleus \\
\hline $\mathrm{PaF}$ & Parafasicular thalamic nucleus \\
\hline PaXi & Paraxiphoid nucleus of thalamus \\
\hline PC & Paracentral thalamic nucleus \\
\hline PIL & Posterior intralaminar thalamic \\
\hline Po & Posterior thalamic nuclear group \\
\hline PoT & Posterior thalamic nuclear group, triangular \\
\hline PPTg & Pedunculotegmental nucleus \\
\hline $\operatorname{PrG}$ & Pregeniculate nucleus of the prethalamus \\
\hline PtPD & Parietal cortex, post, dorsal part \\
\hline PtPR & Parietal cortex, post, dorsal part \\
\hline Reth & Retroethmoid nucleus \\
\hline $\operatorname{RRe}$ & Retroreuniens nucleus \\
\hline Rt & Reticular nucleus (prethalamus) \\
\hline S1 & Primary somatosensory cortex \\
\hline S1BF & Primary somatosensory cortex \\
\hline S1FL & Primary somatosensory cortex \\
\hline $\mathrm{S} 1 \mathrm{HL}$ & Primary somatosensory cortex \\
\hline S1Sh & Primary somatosensory cortex \\
\hline S1Tr & Primary somatosensory cortex \\
\hline S2 & Secondary somatosensory cortex \\
\hline $\mathrm{SNr}$ & Substantia nigra pars reticulata \\
\hline SPF & Subparafascicular thalamic nucleus \\
\hline str & Superior thalamic radiation \\
\hline SubG & Subgeniculate nucleus of the prethalamus \\
\hline VM & Ventromedial thalamic nucleus \\
\hline VO & Ventral orbital cortex \\
\hline VPM & Ventral posteriomedial thalamic \\
\hline VPPC & Ventral posterior nucleus parvicellular \\
\hline $\mathrm{ZI}$ & Zona incerta \\
\hline
\end{tabular}


bioRxiv preprint doi: https://doi.org/10.1101/824250; this version posted October 30, 2019. The copyright holder for this preprint (which was not certified by peer review) is the author/funder. All rights reserved. No reuse allowed without permission. 